\title{
Initial orientation of the fretting fatigue cracks in shrink-fit connection specimens
}

\author{
Ciro Santus \\ DICI - Department of Civil and Industrial Engineering, University of Pisa, Italy \\ ciro.santus@ing.unipi.it, bttp:/ /orcid.org/0000-0003-0859-626X
}

\begin{abstract}
The bending configuration of shrink-fitted connection fretting fatigue tests causes a fluctuation in the contact pressure and in turn a more favourable condition for shear, rather than tensile, crack initiation. According to the classification type I (shear) and type II (tensile) fretting cracks, type II was only observed in the tests with no surface enhancement, which experienced the lowest fretting strength and thus a reduced pressure fluctuation effect. The crack initial direction was predicted as the critical plane orientation undergoing the maximum Fatemi-Socie (FS) stress parameter, for the shallow type I shear cracks. A significant result is that if the critical plane is searched at the fretting hot-spot, an incorrect outward direction is obtained, since the orthogonal direction, with the same shear stress amplitude, experiences a more compressive maximum normal stress. Conversely, with the application of the Point Method, taking the stress location at half the critical distance and by following the potential critical plane, a higher shear stress along the inward direction is obtained. The more compressive stress below the contact can therefore be compensated, and consequently the inward shallow direction is correctly predicted.
\end{abstract}

KEYwORDS. Fretting Fatigue; Initial crack orientation; Multiaxial fatigue criteria; SEM observations.

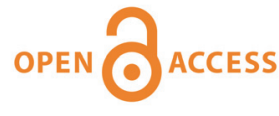

Citation: Santus, C., Initial orientation of the fretting fatigue cracks in shrink-fit connection specimens, Frattura ed Integrità Strutturale, 48 (2019) 442-450.

Received: 28.11 .2018

Accepted: 28.01 .2019

Published: 01.04.2019

Copyright: (C) 2019 This is an open access article under the terms of the CC-BY 4.0, which permits unrestricted use, distribution, and reproduction in any medium, provided the original author and source are credited.

\section{INTRODUCTION}

$\mathrm{F}$ retting fatigue damage is experienced by those elements forced to stay in contact with a fluctuating loading, such as blade dovetail connections of compressor rotors, riveted joints, and shrink-fitted shafts, as summarized by BaiettoDubourg and Lindley [1]. Fretting fatigue can be found at the edge of the contact, where the high contact pressure induces shear traction superimposed on a longitudinal cyclic (bulk) stress on a region which also experiences partial sliding. This loading condition implies complex multiaxial fatigue, usually with inaccurate knowledge of the effective coefficient of friction. Some local micro-wear can also be observed, though the contact interface is usually assumed to be undamaged, i.e. the nominal geometry. 
There are several methodologies for fretting fatigue tests in the literature, as introduced by Hills and Nowell [2] and more recently discussed by De Pauw et al. [3]. Full-scale testing is a viable solution, for example as proposed by Azevedo et al. [4] for overhead conductor application, and by Santus [5] for oil drilling tubular connections. Alternatively, the floating fretting bridge configuration has been implemented, such as by Swalla and Neu [6], Mutoh and Xu [7] and Liu and Hill [8], where the specimen resembles a (plain) tensile coupon and a proving ring is applied to generate the lateral load and then control the contact pressure. However, with this solution, the two pad contacts of the bridge can experience different levels of slippage. This issue can be eliminated with the fixed solution, in which one side of the bridge is attached through an element of specific stiffness to the relatively rigid frame of the testing machine. This solution is quite common in laboratories, indeed there are several examples of this test rig setup, such as Szolwinski and Farris [9], Muñoz et al. [10], Araújo and Castro [11], Baietto et al. [12], De Pauw et al. [13], Hojjati-Talemi et al. [14], Vázquez et al. [15]. Other test setups have also been proposed, resembling the component under the actual load, still loaded with a laboratory testing machine, such as by Golden et al. [16,17] for blade dovetail connections. This approach was also followed for the shrinkfitted shaft-hub connection by Juuma [18,19], Alfredsson [20], Lanoue et al. [21], and finally by Bertini and Santus, and Bertini et al. [22,23].

There is experimental evidence of fretting crack paths in the literature, such as by Szolwinski and Farris [9], Swalla and Neu [6], Muñoz et al. [10], and Proudhon et al. [24]. The common evidence is that the crack orientation is almost always below the contact or, in other words, the crack direction is inward, however, with different angles. Around 20 years ago, Lamacq and Dubourg began investigating the early stages of fretting cracks [25,26]. In their papers, two types of crack initiations were defined: type I and type II, and this distinction was in relation to the crack initial orientation, which in turn suggested the kind of load causing the crack. Though both types of crack are inward, the type I crack is defined as initiating at a very shallow angle with respect to the surface, while type II cracks are observed as almost perpendicular to the contact profile. Therefore, the type II cracks are promoted by the cyclic tensile load, while the former can be assumed as being generated by the cyclic shear load.

Proudhon et al. [24] provide a three-dimensional experimental visualization using X-ray micro-tomography, showing a clear example of a type II crack. In fact, despite some unavoidable material source of irregularity, the path was almost perpendicular to the surface with a small orientation inward below the contact. Type I cracks tend to initiate inside the contact slip regions, while type II cracks can be observed at the edge of the contact, or even slightly outside the contact where the tensile normal stress amplitude is still high. However, for both crack types, the orientation gradually turns perpendicular to the fretting surface after kinking or even some branching. In fact, the crack propagation is predominantly mode I when it is far from the stress concentration and the multiaxiality stress state induced by the contact.

The initial propagation path of the fretting cracks has recently been modelled by several researchers, since it is key to a deeper understanding of fretting mechanics. Giner et al. [27] proposed the use of the Extended Finite Element Method (X-FEM) to introduce crack at the contact edge, without needing to re-mesh the model. The Erdogan and Sih criterion, or Maximum Tangential Stress (MTS), was followed by them and the modelled crack orientation resulted to grow outward the contact below the fretting surface, especially for low bulk stress values, thus not in agreement with the general trend of fretting fatigue cracks. Giner et al. [28] then assumed that the observed cracks were type II (i.e. tensile, in line with the Lamacq and Dubourg's definition) as evident from their experiment, and they correctly predicted the initial orientation by selecting the angle for which the normal stress amplitude was maximum. After this initiation analysis, the X-FEM technique was again implemented, and the criterion of minimum shear stress range was applied to determine the angle for each step increment of the crack. The direction with the maximum normal stress amplitude was selected, from the two orthogonal directions for which the shear stress amplitude was minimum (close to zero). The predicted path was almost perpendicular to the surface, slightly inward with respect to the contact, and thus in good agreement with the experiments. Majzoobi and Abbasi [29,30] proposed setting the initial orientation in line with the experimental evidence, without proposing a criterion for the initial orientation, and then followed the Erdogan and Sih (MTS) criterion for the further propagation. The path obtained was inward with an angle of approx. $45^{\circ}$, though significantly dependent on the load phase, and a more inclined (inward) angle was found for the out-of-phase loading, thus obtaining a clear type I crack. Navarro et al. [31] tested the Fatemi-Socie (FS) and the Smith-Watson-Topper (SWT) critical plane approaches by averaging the stresses along an initial straight path. They found that the SWT parameter better correlated the angle in the very initial stage $(20 \mu \mathrm{m})$, in agreement with the type II (tensile) crack, while FS predicted either an outward or inward crack, with a $90^{\circ}$ angular distance. However, even the inward path was not in agreement with the experimental evidence as the predicted orientation was at a too largely inclined angle. Nevertheless, in the same series of tests, another specimen had an initial path inward which was reasonably classified as type I (shear). Araújo et al. [32] compared the SWT, FS and also the Modified Wöhler Curve Method (MWCM) criteria and considered different methods for averaging the rapidly changing stress distributions below the fretting surface, resembling the approach by Vantadori et al. [33], and Fouvry et al. 
[34]. Though type I and type II cracks where not differentiated, they discussed several anomalies between the experimental orientation of the crack and the predictions, and an intermediate experimental crack angle, with respect to the SWT (tensile) and the FS or MWCM (shear) criteria, was observed in one case. The normal stress component for the correction of both FS and MWCM criteria can play a role in distinguishing between the two equal maximum shear stress amplitude directions, at an angular distance of $90^{\circ}$. This is of great interest for this kind of analysis, especially considering that the crack orientation outward, which can be predicted as an effect of the normal stress correction, is very rarely observed.

In this paper the fretting fatigue tests, which we previously presented in Bertini and Santus [22], are reconsidered and the initial crack orientation, evident by means of Scanning Electron Microscope (SEM) observations, is discussed by comparing these approaches proposed in the literature. The main interest of these tests is that the contact pressure fluctuates with the bulk bending load, which causes the tensile stress to be less predominant than in the usual test rigs where the pressure remains (almost) constant during the fretting cycle. Consequently, the observed cracks are clearly oriented with a shallow, or even very shallow, initiation angle towards the inside of the contact thus obviously type I (shear) cracks.

\section{EXPERIMENTAL TESTS}

he setup of the fretting experimental tests investigated in this paper is shown in Fig. 1 (a), following our previous work: Bertini and Santus [22]. The specimen shaft is manufactured in aluminium alloy 7075-T6, with a conical end which is then shrink-fitted into a steel hub, allowing the connection shrinkage intensity to be controlled with an adjusting nut. The alternating load was applied at the other side, with a hydraulic actuator, and for all the tests the load ratio of this remote force was $R=-1$. The fretting crack nucleated at the edge of the "flat and rounded" contact, which can be assumed as (locally) plane strain.

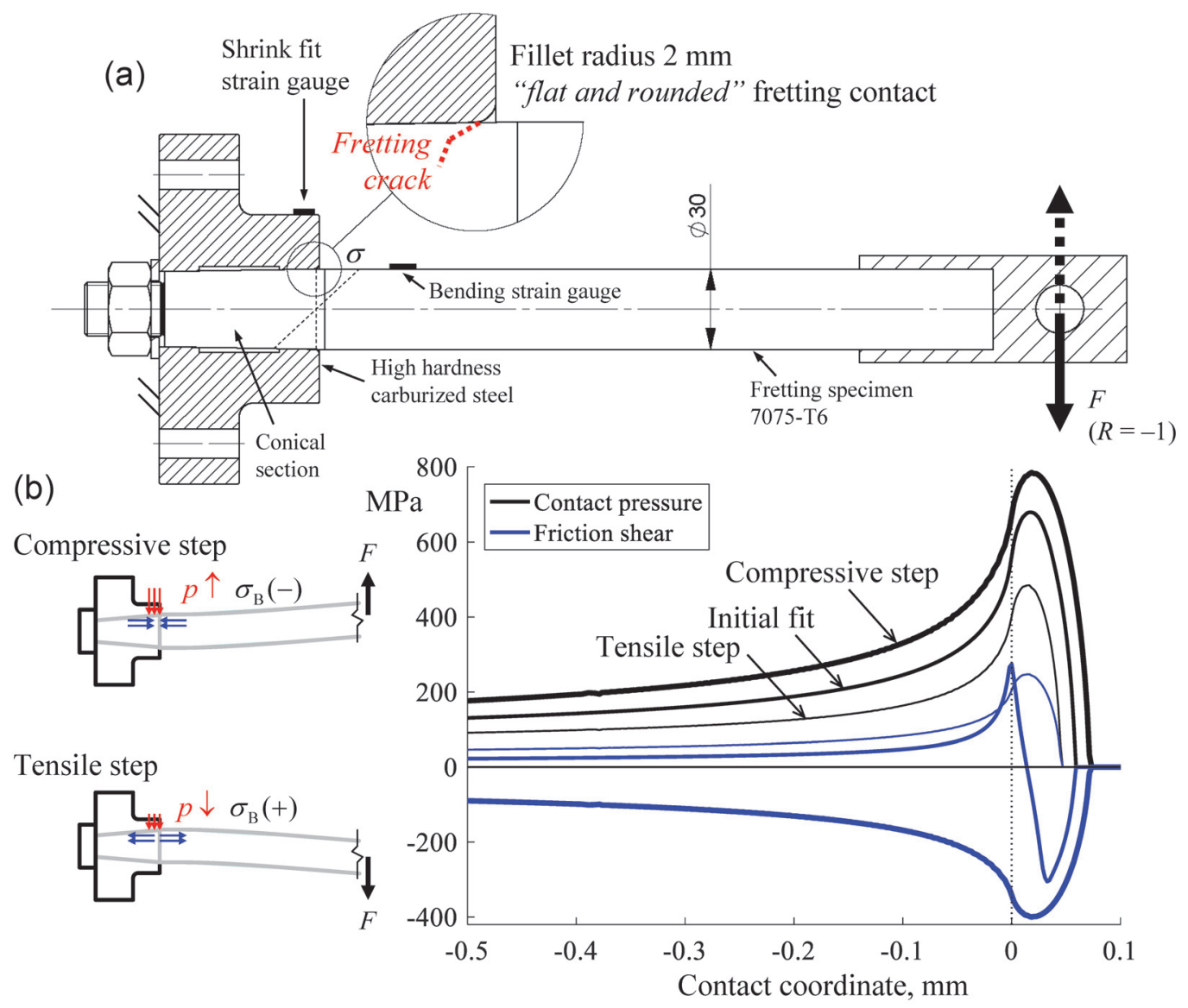

Figure 1: (a) Fretting test setup for shrink-fitted shaft-hub connection, geometry details and (b) contact pressure fluctuation at the fretting hot-spot during the loading cycle. 
In order to monitor the test, two strain gauges were applied: one on the hub along the hoop direction, and the other at a certain position along the shaft. The former strain gauge was used to control the shrinkage, while the latter to better control the cyclic bending, though a load cell was also placed between the actuator and the shaft loading joint. This configuration resembles a common connection between a shaft and any mechanical wheel with a radial interference, loaded under cyclic bending. For this reason, this setup can be considered a component-like test rig, however, still based on the fixed bridge configuration, where the contact bridge is provided by the axisymmetric pad. Complete knowledge of the stress history can be obtained by means of Finite Element (FE) simulations, along with an accurate monitoring of the load through the strain gauges. A significant difference between this test rig, with respect to the usual fixed bridge configuration on a universal testing machine, is that the fluctuating bending load causes non-constant contact pressure during the fretting cycle. Indeed, at the fretting region, the pressure distribution intensity is higher during the compressive half-cycle and lower during the tensile phase, Fig. 1 (b). Similarly, Abbasi and Majzoobi [30] recently proposed a test rig setup in which the contact load was variable and with a controlled phase with respect to the bulk load. The fluctuating contact pressure is not usually wanted in laboratory fretting tests, in fact the contact fluctuation is prevented with two large compliant elements, or a single one, as shown in the setup proposed by Giner et al. [28], or similarly by means of a proving ring. Nevertheless, this feature can be a realistic representation of some fretting applications.

The fretting test results are reported in Fig. 2, where three series are compared with evident strength differences. The surface preparation conditions are: (i) no modification of the fretting interface (as is), (ii) with lubrication applied to the contact surface before being connected to the hub, and finally (iii) with Deep Rolling applied to the shaft, according to the treatment parameter investigation reported by Beghini et al. [35].

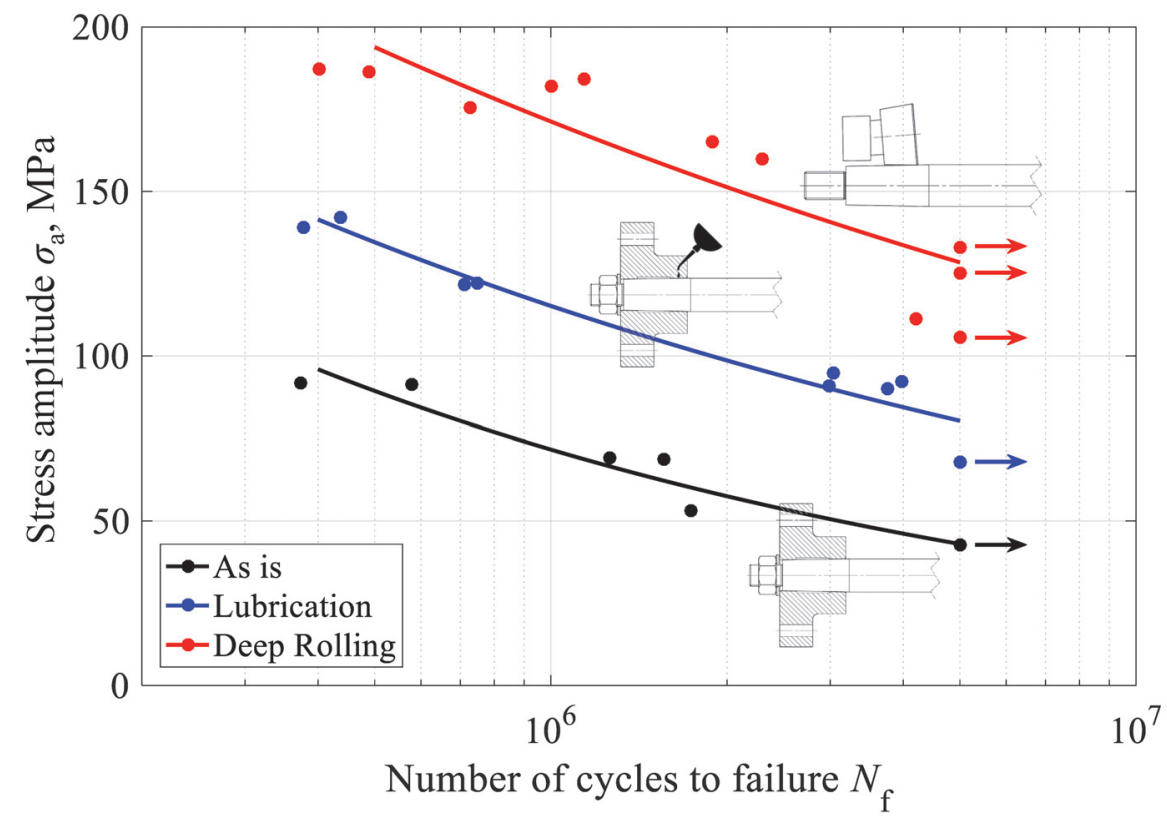

Figure 2: Fatigue test results of three series: surface as is, contact lubrication, and Deep Rolling applied to the shaft.

In Fig. 3 the fretting cracks at their initial stage are shown after sectioning runout specimens. These cracks are not perfectly straight. However, a unique approximated orientation can be defined, except for the first case where a significant deflection can be observed after very few microns, which can be considered as the stage I to stage II transition. The orientation angles were evaluated according to the sign specification shown in the top of the figure, where $\alpha=0^{\circ}$ means a perpendicular orientation, negative $\alpha$ is inward and positive is outward. As discussed above, the lowering of the contact pressure during the tensile phase of the fretting cycle inhibited the onset of type II (tensile) cracks, and again this type of crack was further prevented by the compressive residual stress distribution for the Deep Rolling series. For these latter tests, several initiated cracks were evident, and of these, the inner cracks also showed a shallower angle than those at the trailing edge of the contact. Finally, micro-wear due to the pressure concentration and the cyclic slippage was evident at the edge of the contact, especially for the Deep Rolling specimens which underwent a higher fretting loading. This effect was not considered in the FE analysis reported below, though the surface modification may obviously play a role in terms of the contact pressure, thus affecting the subsurface stress distribution. 


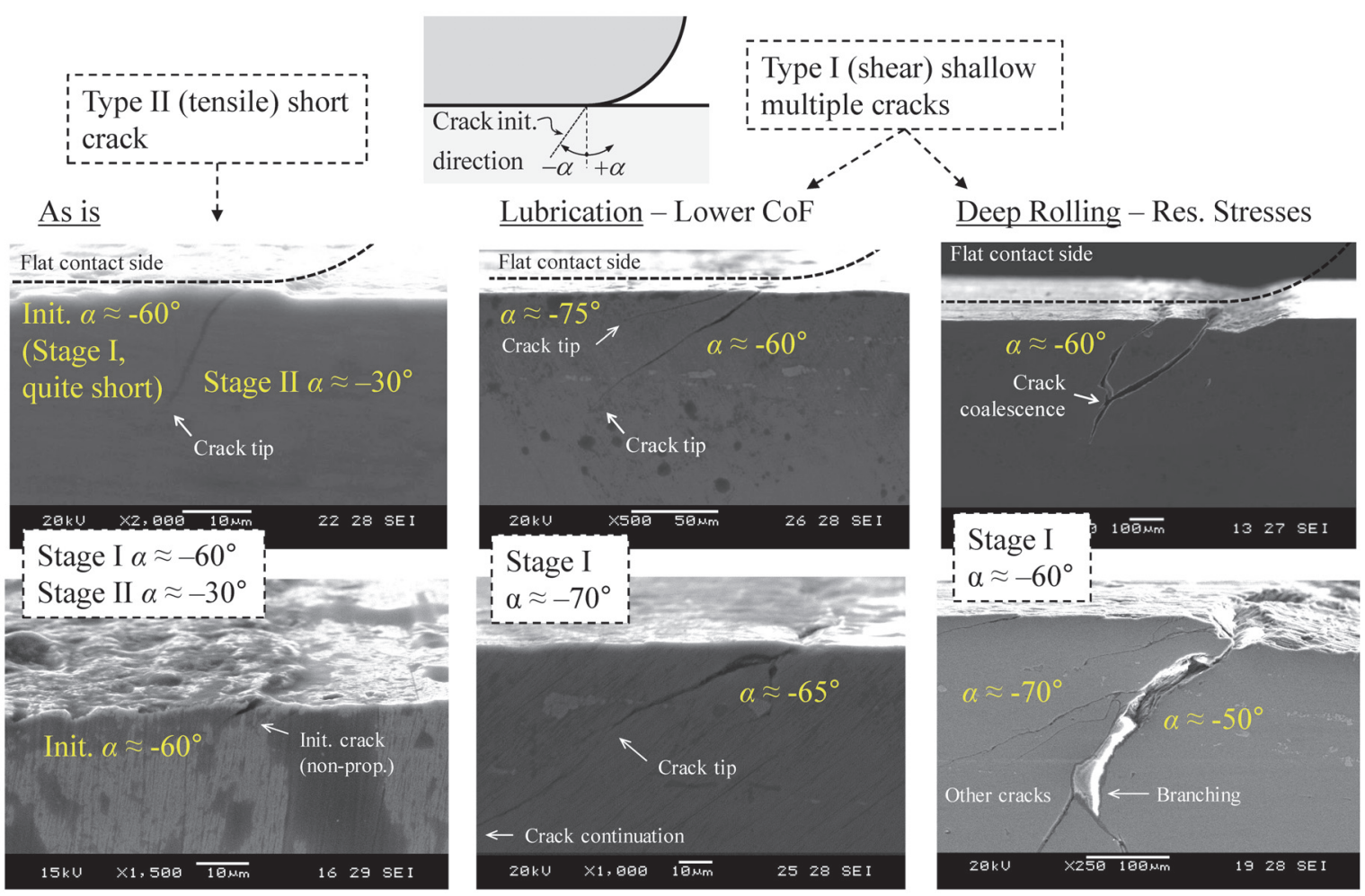

Figure 3: SEM observations of the initial cracks and evaluation of the orientation angles of two runout specimens for each series.

\section{PREDICTION OF THE CRACK INITIAL ORIENTATION}

7 he stress distribution at the fretting region is multiaxial, high gradient and singular when the contact is not rounded. For this reason, the Theory of Critical Distances (TCD) is usually applied in the literature along with a multiaxial critical plane method, such as the FS or the MWCM criteria which are shear based, thus they are expected to accurately predict type I shear cracks. On the other hand, the tensile type II is supposed to be better correlated with the SWT, which is a uniaxial based criterion. These two common criteria are formalized as:

$$
\begin{aligned}
& \mathrm{FS}=\tau_{\mathrm{a}}\left(1+k \frac{\sigma_{\mathrm{n}, \max }}{\sigma_{\mathrm{Y}}}\right) \\
& \mathrm{SWT}=\sqrt{\sigma_{\mathrm{n}, \mathrm{a}} \sigma_{\mathrm{n}, \max }}
\end{aligned}
$$

where the stress components are graphically defined in Fig. 5: $\tau_{\mathrm{a}}$ and $\sigma_{\mathrm{n}, \mathrm{a}}$ are the shear and the normal stress amplitudes, respectively, experienced by any possible critical plane and $\sigma_{\mathrm{n}, \max }$ is the maximum normal stress on the same plane. $\sigma_{\mathrm{Y}}$ is the yield strength, and $k$ is a coefficient which controls the mean stress effect.

This material parameter $k=0.44$ was derived from the fretting analysis by Vázquez et al. [15], considering the same alloy and similar treatment 7075-T651. The critical distance length for the aluminium alloy 7075-T6 was recently obtained in our previous work: Santus et al. [36,37], both according to the primary SIF threshold definition and then proposing an alternative inverse search procedure with an optimized specimen. The threshold-based value obtained for the load ratio $R$ $=-1$ is:

$$
L=\frac{1}{\pi}\left(\frac{\Delta K_{\mathrm{th}}}{\Delta \sigma_{\mathrm{fl}}}\right)^{2}=0.056 \mathrm{~mm}
$$


where $\Delta K_{\mathrm{th}}$ is the threshold stress intensity factor range and $\Delta \sigma_{\mathrm{fl}}$ the (plain specimen) fatigue limit range.

When the FS parameter is considered at the fretting hot-spot, as discussed in the Introduction, there are two directions of maximum shear stress amplitude, at an angular distance of $90^{\circ}$, shown in Fig. 4. The direction of maximum FS parameter is close to the one that, between these two perpendicular planes, undergoes the highest maximum normal stress. Despite the usual evidence of inward crack orientation, the outward direction is more aligned with the tensile stress induced by the bulk load, while the inward direction more significantly experiences the normal compressive stress produced by the contact pad. For this reason, the stress analysis at the hot-spot can lead to a misleading crack direction prediction.

(a)

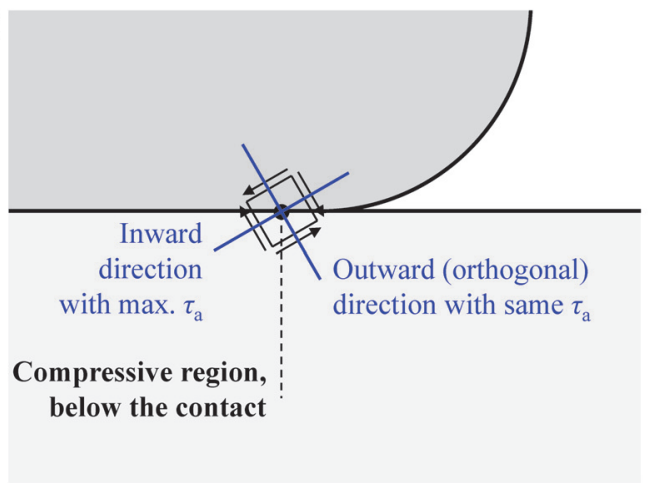

(b)

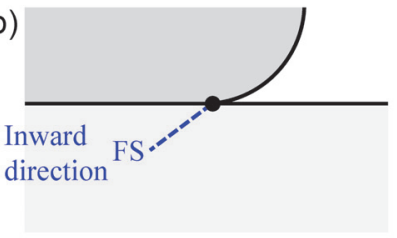

(c)

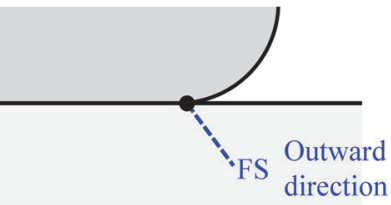

Figure 4: (a) Critical plane analysis at the fretting hot-spot, the two perpendicular maximum shear stress amplitude directions can drive the FS prediction either Inward (b) or Outward (c) depending on the maximum normal stress.

Following the Point Method (PM) of the TCD, the stresses can be evaluated at the location $L / 2$ along any notch bisector. For the present fretting geometry, a vertical line starting from the hot-spot can be considered instead of the bisector, Fig. 5 (a). The results obtained with this assumption are not graphically reported for the sake of brevity. Although the stresses are lower than those obtained at the hot-spot, between the two normal directions with maximum shear stress amplitude, the outward direction still experiences the highest FS parameter, thus again the crack orientation prediction turns out to be inaccurate. Better results are obtained if the $L / 2$ stress point is considered, not just at a fixed location below the hotspot, but following the (potential) crack plane, shown in Fig. 5 (b), which better identifies the stresses along the crack line before its formation. When this stress evaluation point is placed below the contact pad, rather than along any other outward direction, the normal stress is more compressive. However, the shear stress amplitude at two perpendicular directions is no longer equal, whereas it is higher along the inward direction. For this reason, this latter modelling approach is more promising, and thus followed in the test analysis reported hereafter.

Point Method

(a)

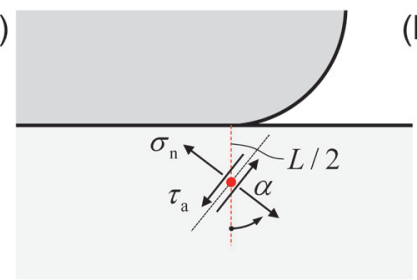

Point Method

(following the critical plane)

(b)

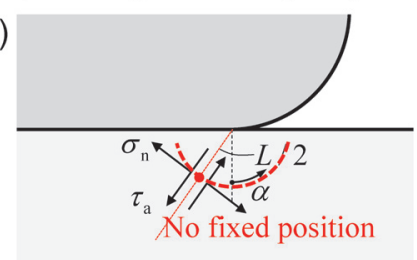

Figure 5: Multiaxial applications of the Point Method to the fretting problem: (a) the considered point is at $L / 2$ and perpendicularly below the surface, (b) the point is still at $L / 2$ but following the (possible) critical plane orientation.

Short non-propagating cracks were observed at the runout specimens of the first series (as is), with an initial very shallow inclination. If the maximum FS parameter is searched at the fretting hot-spot, as discussed above, the predicted crack orientation is outward. On the other hand, the negative inclination agrees with a high shear stress amplitude, however, the normal stress is less tensile in this angular region. Finally, the SWT prediction is very close to the perpendicular direction, and thus again not in good agreement with the evidence, (see Fig. 6 (b)). After an initial propagation of a few microns, the orientation is more perpendicular to the fretting surface, and the crack angle can be assumed as approx. $\alpha=30^{\circ}$. According to the PM analysis with no fixed position, introduced in Fig. 5 (b), this angle is in agreement with the 
maximum normal stress amplitude $\sigma_{\mathrm{n}, \mathrm{a}}$ orientation, confirming the tensile type of this crack. However, the SWT parameter vanishes, since for this angle the maximum normal stress is zero, as evident in Fig. 6 (c).
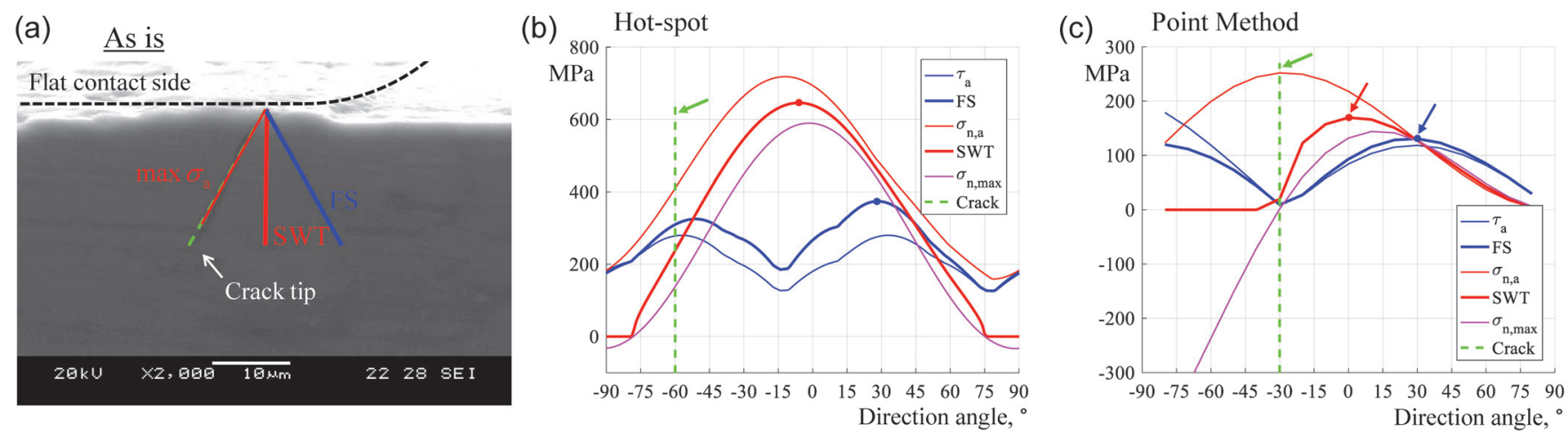

Figure 6: (a) Crack evidence and initial orientation predictions for the as is series. (b) Stress analysis at the hot-spot, and (c) with the no fixed position Point Method.

(a) Lubrication - Lower $\mathrm{CoF}$

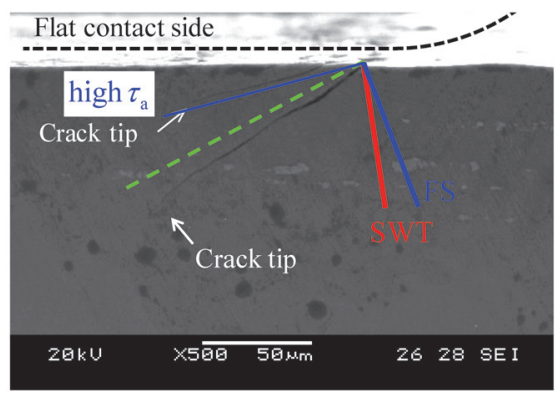

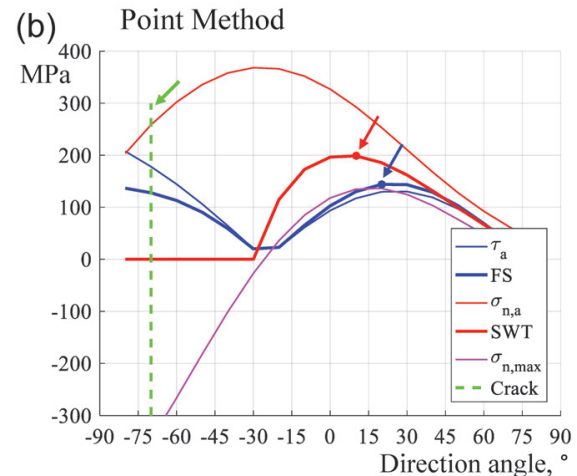

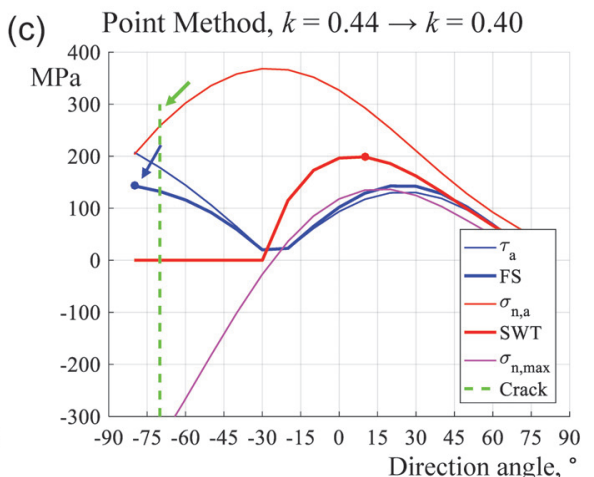

Figure 7: (a) Crack evidence and initial orientation prediction for the Lubrication series. (b) Stress analysis with the no fixed position Point Method. (c) Repeated analysis with a lower FS material parameter.
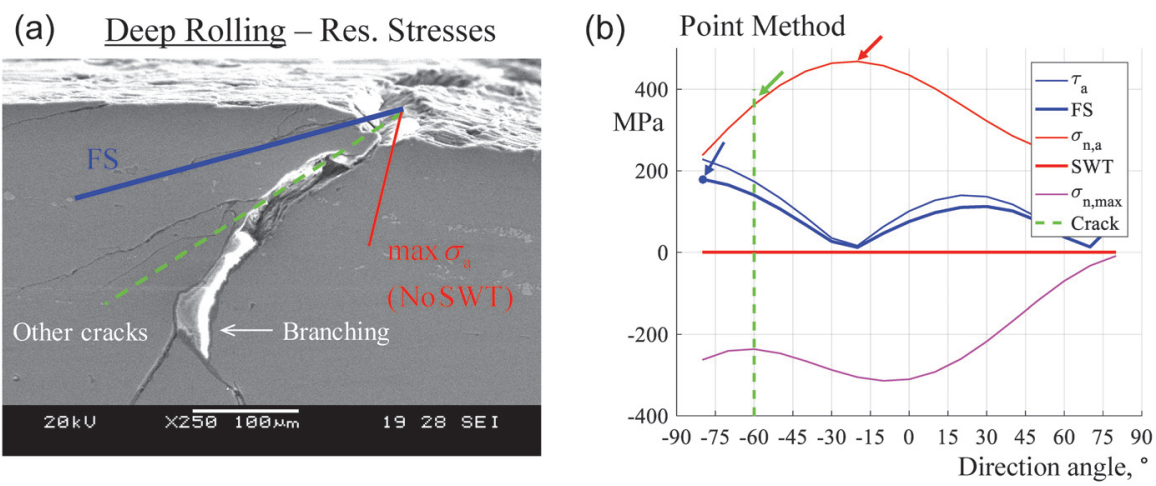

Figure 8: (a) Crack evidence and initial orientation predictions for the Deep Rolling series. (b) Stress analysis with the no fixed position Point Method.

Very shallow cracks were found for the Lubrication series with a clear inward direction, and without any apparent stage I to stage II transition. Again, the SWT and FS at the hot-spot predicted outward directions by considering the critical plane orientations where these two parameters are maximum, shown in Fig. 7 (b), and a similar conclusion was obtained with the fixed position PM described in Fig. 5 (a). However, by considering the implementation of the PM with no fixed evaluation point, as in Fig. 5 (b), the shear stress amplitude is very high for negative angles, while the maximum FS is still approximately perpendicular to the actual direction of the crack, due to the tensile maximum normal stress. A good correlation can thus be found if a lower value of the FS material parameter is assumed, such as $k=0.40$, instead of the 
literature value $k=0.44$, Fig. 7 (c). Consequently, the role of the normal stress is less weighty with respect to the shear stress amplitude.

Finally, the maximum normal stress is negative for any orientation angle of the Deep Rolling test, shown in Fig. 8 (b). The SWT parameter cannot be calculated, and the orientation of the maximum normal stress amplitude is inward but not in agreement with the evidently more inclined cracks. The maximum of the FS parameter is less affected by the normal stress, and thus can be found in the negative angle region, still with $k=0.44$, and in quite good agreement with the actual overall orientation of the cracks.

\section{CONCLUSIONS}

7 ype I (shear) crack fretting fatigue initiation was experimentally observed with SEM visualizations of sectioned shrink-fit connection specimens with increased strength, both by lubricating the contact surface and with Deep Rolling. The prediction analysis of the initial crack orientation angle was proposed in the paper. Despite the apparent agreement between the inward crack orientation and the direction of maximum shear stress amplitude, concern was raised regarding the correct prediction of this or the other (outward) orthogonal orientation, which experiences a more tensile normal stress. The value of the Fatemi-Socie material parameter can drive the predicted direction inward or outward by controlling the effect of the maximum normal stress. On the other hand, a type II (tensile) crack was only observed for the fretting configuration with no surface preparation, which underwent a lower fretting load and thus less of contact pressure decrease during the tensile load cycle, which instead promoted type I shallow cracks.

\section{REFERENCES}

[1] Baietto-Duborg, M.-C., Lindley, T. (2013). Fretting Fatigue: Modeling and Applications. Fatigue of Materials and Structures, Hoboken, NJ, USA, John Wiley \& Sons, Inc., pp. 195-230.

[2] Hills, D.A., Nowell, D. (1994). Mechanics of Fretting Fatique, vol. 30, Dordrecht, Springer Netherlands.

[3] De Pauw, J., De Baets, P., De Waele, W. (2011). Review and Classification of Fretting Fatigue Test Rigs, Sustain. Constr. Des., 2, pp. 41-52.

[4] Azevedo, C.R.F., Henriques, A.M.D., Pulino Filho, A.R., Ferreira, J.L.A., Araújo, J.A. (2009). Fretting fatigue in overhead conductors: Rig design and failure analysis of a Grosbeak aluminium cable steel reinforced conductor, Eng. Fail. Anal., 16(1), pp. 136-151, DOI: 10.1016/j.engfailanal.2008.01.003.

[5] Santus, C. (2008). Fretting fatigue of aluminum alloy in contact with steel in oil drill pipe connections, modeling to interpret test results, Int. J. Fatigue, 30(4), pp. 677-688, DOI: 10.1016/j.ijfatigue.2007.05.006.

[6] Swalla, D.R., Neu, R.W. (2001). Influence of coefficient of friction on fretting fatigue crack nucleation prediction, Tribol. Int., 34(7), pp. 493-503, DOI: 10.1016/S0301-679X(01)00048-2.

[7] Mutoh, Y., Xu, J.-Q. (2003). Fracture mechanics approach to fretting fatigue and problems to be solved, Tribol. Int., 36(2), pp. 99-107, DOI: 10.1016/S0301-679X(02)00136-6.

[8] Liu, K.K., Hill, M.R. (2009). The effects of laser peening and shot peening on fretting fatigue in Ti-6Al-4V coupons, Tribol. Int., 42(9), pp. 1250-1262, DOI: 10.1016/j.triboint.2009.04.005.

[9] Szolwinski, M.P., Farris, T.N. (1998). Observation, analysis and prediction of fretting fatigue in 2024-T351 aluminum alloy, Wear, 221(1), pp. 24-36, DOI: 10.1016/S0043-1648(98)00264-6.

[10] Muñoz, S., Navarro, C., Domínguez, J. (2007). Application of fracture mechanics to estimate fretting fatigue endurance curves, Eng. Fract. Mech., 74(14), pp. 2168-2186, DOI: 10.1016/j.engfracmech.2006.10.010.

[11] Araújo, J.A., Castro, F.C. (2012). A comparative analysis between multiaxial stress and $\Delta K$-based short crack arrest models in fretting fatigue, Eng. Fract. Mech., 93, pp. 34-47, DOI: 10.1016/j.engfracmech.2012.06.007.

[12] Baietto, M.C., Pierres, E., Gravouil, A., Berthel, B., Fouvry, S., Trolle, B. (2013). Fretting fatigue crack growth simulation based on a combined experimental and XFEM strategy, Int. J. Fatigue, 47, pp. 31-43, DOI: 10.1016/j.ijfatigue.2012.07.007.

[13] De Pauw, J., De Waele, W., Hojjati-Talemi, R., De Baets, P. (2014). On the use of digital image correlation for slip measurement during coupon scale fretting fatigue experiments, Int. J. Solids Struct., 51(18), pp. 3058-3066, DOI: $10.1016 /$ j.ijsolstr.2014.05.002.

[14] Hojjati-Talemi, R., Abdel Wahab, M., De Pauw, J., De Baets, P. (2014). Prediction of fretting fatigue crack initiation and propagation lifetime for cylindrical contact configuration, Tribol. Int., 76, pp. 73-91, 
DOI: 10.1016/j.triboint.2014.02.017.

[15] Vázquez, J., Navarro, C., Domínguez, J. (2017). Analysis of fretting fatigue initial crack path in Al7075-T651 using cylindrical contact, Tribol. Int., 108, pp. 87-94, DOI: 10.1016/j.triboint.2016.09.023.

[16] Golden, P.J., Calcaterra, J.R. (2006). A fracture mechanics life prediction methodology applied to dovetail fretting, Tribol. Int., 39(10), pp. 1172-1180, DOI: 10.1016/j.triboint.2006.02.006.

[17] Golden, P.J., Shepard, M.J. (2007). Life prediction of fretting fatigue with advanced surface treatments, Mater. Sci. Eng. A, 468-470, pp. 15-22, DOI: 10.1016/j.msea.2006.10.168.

[18] Juuma, T. (1999). Torsional fretting fatigue strength of a shrink-fitted shaft, Wear, 231(2), pp. 310-318, DOI: $10.1016 / S 0043-1648(99) 00249-5$.

[19] Juuma, T. (2000). Torsional fretting fatigue strength of a shrink-fitted shaft with a grooved hub, Tribol. Int., 33(8), pp. 537-543, DOI: 10.1016/S0301-679X(00)00102-X.

[20] Alfredsson, B. (2009). Fretting fatigue of a shrink-fit pin subjected to rotating bending: Experiments and simulations, Int. J. Fatigue, 31(10), pp. 1559-1570, DOI: 10.1016/j.ijfatigue.2009.04.019.

[21] Lanoue, F., Vadean, A., Sanschagrin, B. (2011). Fretting fatigue strength reduction factor for interference fits, Simul. Model. Pract. Theory, 19(9), pp. 1811-1823, DOI: 10.1016/j.simpat.2011.05.004.

[22] Bertini, L., Santus, C. (2015). Fretting fatigue tests on shrink-fit specimens and investigations into the strength enhancement induced by deep rolling, Int. J. Fatigue, 81, pp. 179-190, DOI: 10.1016/j.ijfatigue.2015.08.007.

[23] Bertini, L., Santus, C., Merlo, A., Bandini, M. (2016). A fretting fatigue setup for testing shrink-fit connections and experimental evidence of the strength enhancement induced by deep rolling, Proc. Inst. Mech. Eng. Part C J. Mech. Eng. Sci., 230(9), pp. 1432-1439, DOI: 10.1177/0954406215612817.

[24] Proudhon, H., Buffière, J.-Y., Fouvry, S. (2007). Three-dimensional study of a fretting crack using synchrotron X-ray micro-tomography, Eng. Fract. Mech., 74(5), pp. 782-793, DOI: 10.1016/j.engfracmech.2006.06.019.

[25] Lamacq, V., Dubourg, M.-C., Vincent, L. (1997). A theoretical model for the prediction of initial growth angles and sites of fretting fatigue cracks, Tribol. Int., 30(6), pp. 391-400, DOI: 10.1016/S0301-679X(96)00068-0.

[26] Lamacq, V., Dubourg, M.-C. (1999). Modelling of initial fatigue crack growth and crack branching under fretting conditions, Fatigue Fract. Eng. Mater. Struct., 22(6), pp. 535-542, DOI: 10.1046/j.1460-2695.1999.00173.x.

[27] Giner, E., Sukumar, N., Denia, F.D., Fuenmayor, F.J. (2008). Extended finite element method for fretting fatigue crack propagation, Int. J. Solids Struct., 45(22-23), pp. 5675-5687, DOI: 10.1016/j.ijsolstr.2008.06.009.

[28] Giner, E., Sabsabi, M., Ródenas, J.J., Javier Fuenmayor, F. (2014). Direction of crack propagation in a complete contact fretting-fatigue problem, Int. J. Fatigue, 58, pp. 172-180, DOI: 10.1016/j.ijfatigue.2013.03.001.

[29] Majzoobi, G.H., Abbasi, F. (2017). On the effect of shot-peening on fretting fatigue of Al7075-T6 under cyclic normal contact loading, Surf. Coatings Technol., 328, pp. 292-303, DOI: 10.1016/j.surfcoat.2017.08.067.

[30] Abbasi, F., Majzoobi, G.H. (2018). Effect of out-of-phase loading on fretting fatigue response of Al7075-T6 under cyclic normal loading using a new testing apparatus, Eng. Fract. Mech., 188, pp. 93-111, DOI: 10.1016/j.engfracmech.2017.08.010.

[31] Navarro, C., Vázquez, J., Domínguez, J. (2017). Nucleation and early crack path in fretting fatigue, Int. J. Fatigue, 100, pp. 602-610, DOI: 10.1016/j.ijfatigue.2016.12.028.

[32] Araújo, J.A., Almeida, G.M.J., Ferreira, J.L.A., da Silva, C.R.M., Castro, F.C. (2017). Early cracking orientation under high stress gradients: The fretting case, Int. J. Fatigue, 100, pp. 611-618, DOI: 10.1016/j.ijfatigue.2016.12.013.

[33] Vantadori, S., Fortese, G., Ronchei, C., Scorza, D. (2017). A stress gradient approach for fretting fatigue assessment of metallic structural components, Int. J. Fatigue, 101, pp. 1-8, DOI: 10.1016/j.ijfatigue.2017.04.004.

[34] Fouvry, S., Gallien, H., Berthel, B. (2014). From uni- to multi-axial fretting-fatigue crack nucleation: Development of a stress-gradient-dependent critical distance approach, Int. J. Fatigue, 62, pp. 194-209,

DOI: 10.1016/j.ijfatigue.2013.05.016.

[35] Beghini, M., Bertini, L., Monelli, B.D., Santus, C., Bandini, M. (2014). Experimental parameter sensitivity analysis of residual stresses induced by deep rolling on 7075-T6 aluminium alloy, Surf. Coatings Technol., 254, pp. 175-186, DOI: 10.1016/j.surfcoat.2014.06.008.

[36] Santus, C., Taylor, D., Benedetti, M. (2018). Experimental determination and sensitivity analysis of the fatigue critical distance obtained with rounded V-notched specimens, Int. J. Fatigue, 113, pp. 113-125,

DOI: 10.1016/j.ijfatigue.2018.03.037.

[37] Santus, C., Taylor, D., Benedetti, M. (2018). Determination of the fatigue critical distance according to the Line and the Point Methods with rounded V-notched specimen, Int. J. Fatigue, 106, pp. 208-218,

DOI: 10.1016/j.ijfatigue.2017.10.002. 